\title{
The use of EMLA cream reduces the pain of skin puncture associated with caudal block in children
}

\author{
Eun Kyung Choi ${ }^{1}$, YoungHo Ro ${ }^{1}$, Sung-Sik Park ${ }^{1}$, and Ki-bum Park ${ }^{2}$ \\ Department of Anesthesiology and Pain Medicine, ${ }^{1}$ Kyungpook National University School of Medicine, \\ ${ }^{2}$ Keimyung University School of Medicine, Dongsan Hospital, Daegu, Korea
}

Background: Caudal block is a popular regional anesthesia in children undergoing infraumbilical surgeries including inguinal hernia repair and orchiopexy. We evaluated the efficacy of eutectic mixture of local anesthetic (EMLA) cream for reducing needle insertion pain during caudal block in pediatric patients.

Methods: Forty-one children between the ages of 13 months and 5 years undergoing infraumbilical surgery were randomized to receive either topical EMLA or placebo cream over the sacral hiatus one hour before caudal block. All children were assessed with the Multidimensional Assessment Pain Scale (MAPS) at the following time points. T0: arrival at the operation room; T1: just before needle insertion; T2: immediately after needle insertion into the sacral hiatus. The need for sevoflurane inhalation due to procedural pain response was also assessed at the same time as MAPS assessment. Results: MAPS scores were significantly lower in the EMLA group compared with the placebo group at T2 $(\mathrm{P}=0.001)$. Moreover, need for sevoflurane inhalation due to procedural pain response was significantly lower in the EMLA group compared with the control group at T2 $(\mathrm{P}<0.001)$.

Conclusions: We suggest that pretreatment with EMLA cream over the sacral hiatus before caudal block has significant advantages in alleviating procedure pain during caudal block in children.

Key Words: Caudal anesthesia, EMLA, Pain, Pediatrics.

\section{Introduction}

Caudal block has been traditionally used for postoperative analgesia in children undergoing infraumbilical operations. In

Corresponding author: Ki-bum Park, M.D.

Department of Anesthesiology and Pain Medicine, Keimyung University, Dongsan Hospital, 56, Dalseong-ro, Jung-gu, Daegu 41931, Korea

Tel: 82-53-250-7249, Fax: 82-53-250-7240

E-mail: parkkibum@dsmc.or.kr

ORCID: http://orcid.org/0000-0002-1432-8301

Received: October 28, 2015.

Revised: 1st, November 13, 2015; 2nd, November 20, 2015; 3rd, November 20, 2015; 4th, November 20, 2015; 5th, November 23, 2015.

Accepted: November 23, 2015.

Korean J Anesthesiol 2016 April 69(2): 149-154 http://dx.doi.org/10.4097/kjae.2016.69.2.149 addition to its role of relieving pain after surgery, it has many advantages, including sparing effect of anesthetics and systemic opioids during general anesthesia and as an alternative to general anesthesia which is associated with potential major morbidity [1].

However, inaccurate procedures can lead to disastrous results through intravascular, intraosseous, and intrathecal injections, and nerve damage and block failure may also occur. Dalens et al. [2], reported that the success rate of caudal block at first attempt was approximately $70 \%$. Injection related pain during caudal block may be associated with the success rate and unpredictable complications such as increase in body movement and hemodynamic instability under sedation. Eventually, additional intravenous analgesics or inhalational anesthetics under face mask ventilation are needed.

Eutectic mixture of local anesthetic (EMLA) cream is a topical anesthetic mixture of lidocaine (2.5\%) and prilocaine (2.5\%)

(c) This is an open-access article distributed under the terms of the Creative Commons Attribution Non-Commercial License (http://creativecommons.org/ licenses/by-nc/4.0/), which permits unrestricted non-commercial use, distribution, and reproduction in any medium, provided the original work is properly cited. 
in a cream base [3]. Given its proven efficacy and safety profile, the application of EMLA cream is recommended before vaccination of children to reduce injection related pain [4]. However, the benefit of EMLA cream in reducing venous puncture pain is still under debate [5]. Therefore, we investigated whether the EMLA cream application reduces pain response in the patients who were scheduled to undergo caudal block under sedation, and assessed the incidence of use of sevoflurane as an additional analgesic and sedative to prevent body movement during caudal block.

\section{Materials and Methods}

\section{Study protocol}

This study was approved by the institute ethics committee of our hospital and informed consent was obtained from parents before surgery. Forty-one children who were aged from 13 months to 5 years and weighed under $20 \mathrm{~kg}$, had American Society of Anesthesiologists physical status 1, were undergoing infraumbilical surgery, and who were scheduled to undergo caudal block for procedures such as inguinal hernia and orchiopexy, were enrolled in this study. The patients were excluded if they had a history of allergy to local anesthetics or any components of the EMLA cream, uncertain drug sensitivities, open wound at the application site, severe systemic disease, cardiovascular disease, congenital or idiopathic methemoglobinemia and history of use of analgesics in the last 12 hours.

The patients were randomized into two groups by computer generated random numbers: 1) Placebo group 2) EMLA cream applied group. In the placebo group (Group C), the children were applied an inert placebo cream (Bepanthen ${ }^{\circledR}$, Bayer HealthCare, Leverkusen, Germany) in the size of a coin over the sacral hiatus one hour before caudal block and the site of cream application was covered with $3 \mathrm{M}$ Tegaderm ${ }^{\mathrm{TM}}$ occlusive dressing by an independent anesthesiologist who was not involved in anesthesia administration or pain assessment in the operation room. In the EMLA group (Group E), EMLA cream was applied in the same manner as in the control group. The patients were sedated with intravenous ketamine $1.5 \mathrm{mg} / \mathrm{kg}$ and midazolam $0.1 \mathrm{mg} / \mathrm{kg}$ in the waiting room and were transferred after loss of response to verbal command or gentle touch was confirmed by a second anesthesiologist who assessed the pain score during the procedure. In the operation room, pulse oximetry and noninvasive blood pressure monitoring were applied. Respiratory rate and end-tidal $\mathrm{CO}_{2}$ were monitored via a face mask. After baseline vital signs were checked, caudal block was performed in a Sim's position using a $22 \mathrm{G}$ needle under $50 \%$ oxygen through a face mask by one skilled anesthesiologist who was not aware of the kind of cream applied. Caudal epidural solution was prepared with $1 \%$ lidocaine and $5 \mu \mathrm{g} / \mathrm{ml}$ epinephrine. The solution was administered at $1 \mathrm{ml} / \mathrm{kg}$ after the confirmation of correct needle placement by aspiration.

Pain assessment was evaluated by the Multidimensional Assessment Pain Scale (MAPS) [6] at the following time points: T0: baseline values obtained in the operation room; T1: just before needle insertion into the sacral hiatus; T2: immediately after needle insertion into the sacral hiatus. If the needle was misplaced by movements of the patients due to pain, an assistant held the patient gently to prevent events such as injury due to fall. Five categories are included within the MAPS: vital signs (heart rate and/or blood pressure), breathing patterns, facial expression, body movements, and state of arousal (Table 1). Each category is graded on a three-point scale $(0,1,2)$, and total scores range from 0 (no pain) to 10 (extreme pain). Then, 2-3\% sevoflurane was given through a face mask when rigid and/or limited body movement occurred as the needle was advanced into the sacral hiatus because any movement affected caudal block and caused block failure. As the end-tidal concentration of sevoflurane was similar to the administered concentration, caudal block was continued. Incidence of use of sevoflurane was also assessed during caudal block. The patients maintained

Table 1. The Multidimensional Assessment Pain Scale

\begin{tabular}{|c|c|c|c|}
\hline Categories & 0 & 1 & 2 \\
\hline $\begin{array}{l}\text { Vital signs } \\
\text { Heart rate and/or Blood pressure }\end{array}$ & Within baseline & $\begin{array}{l}\text { Increase of more than } 10 \text { beats/min } \\
\text { and/or increase of more than } \\
10 \mathrm{mmHg}\end{array}$ & $\begin{array}{l}\text { Decrease of more than } 10 \text { beats/min } \\
\text { and/or decrease of more than } \\
10 \mathrm{mmHg}\end{array}$ \\
\hline Breathing pattern & No change & $\begin{array}{l}\text { Development or increase in } \\
\text { respiratory distress }\end{array}$ & Severe respiratory distress \\
\hline Facial expressions & Relaxed & Grimace & $\begin{array}{l}\text { Grimace associated with silent or } \\
\text { weak cry }\end{array}$ \\
\hline Body movements & $\begin{array}{l}\text { No movements or } \\
\text { purposeful movements }\end{array}$ & Restless & $\begin{array}{l}\text { Rigid and/or limited body } \\
\text { movements }\end{array}$ \\
\hline State of arousal & Calm or asleep & Hyperreactive & Shut down \\
\hline
\end{tabular}


spontaneous ventilation with $50 \%$ oxygen via a face mask. If oxygen saturation decreased to less than $90 \%$ due to over sedation or breath holding due to procedural pain, assisted ventilation was performed. After caudal block was performed, oxygen and $1 \%$ sevoflurane were supplied via a face mask regardless of the groups to induce sedation during the operation. If analgesia was insufficient for the operation, fentanyl $0.5-1.0 \mu \mathrm{g} / \mathrm{kg}$ was administered. We observed the patients for any complications such as local skin reactions, toxicity of local anesthetics or anesthesiarelated complications in the post anesthetic care unit (PACU) until discharge.

\section{Statistical analysis}

Data analysis was performed using statistical software (SPSS, version 18.0 for Windows; SPSS Inc., Chicago, IL, USA). All data were expressed as the mean $\pm \mathrm{SD}$. Comparison between the two groups was performed using Student's t-test, Mann-Whitney $\mathrm{U}$-test, and $x^{2}$-test as appropriate. Statistical significance was accepted at a $\mathrm{P}$ value $<0.05$. Our primary outcome was MAPS scores after the needle was advanced into the sacral hiatus. Sample size was determined based on a preliminary study. An MAPS score $\geq 4$ was considered as a significant pain response caused by advancement of the needle into the sacral hiatus. Forty patients were required to show that the percentage of patients with MAPS score $\geq 4$ decreased from $80 \%$ in Group C to $40 \%$ in

Table 2. Patient Demographic Data

\begin{tabular}{lccc}
\hline & $\begin{array}{c}\text { Group C } \\
(\mathrm{n}=21)\end{array}$ & $\begin{array}{c}\text { Group E } \\
(\mathrm{n}=20)\end{array}$ & P value* \\
\hline Male/female (n) & $16 / 5$ & $17 / 3$ & $\mathrm{NS}$ \\
Age (months) & $35.2 \pm 15.6$ & $33.0 \pm 13.1$ & $\mathrm{NS}$ \\
Height $(\mathrm{cm})$ & $96.2 \pm 8.4$ & $92.5 \pm 10.8$ & $\mathrm{NS}$ \\
Weight $(\mathrm{kg})$ & $14.5 \pm 2.8$ & $13.6 \pm 2.9$ & $\mathrm{NS}$ \\
Duration of surgery (min) & $30.6 \pm 9.8$ & $32.4 \pm 8.7$ & $\mathrm{NS}$ \\
Duration of anesthesia (min) & $49.8 \pm 12.7$ & $48.7 \pm 10.4$ & $\mathrm{NS}$ \\
\hline
\end{tabular}

Data are presented as number or mean \pm SD. Group C: Placebo group, Group E: EMLA group, NS: no significant differences. *Student's t-test or $x^{2}$-test as appropriate.

Table 3. Comparison of the Multidimensional Assessment Pain Scale

\begin{tabular}{cccc}
\hline & Group C $(\mathrm{n}=21)$ & Group E $(\mathrm{n}=20)$ & P value* $^{*}$ \\
\hline T0 & 2.0 & 2.0 & NS \\
T1 & $2.1 \pm 0.4$ & $2.1 \pm 0.2$ & NS \\
T2 & $4.5 \pm 1.0$ & $3.3 \pm 1.0$ & 0.001 \\
\hline
\end{tabular}

Data are presented as Mean \pm SD. Group C: Placebo group, Group E: EMLA group, T0: baseline values, T1: before needle insertion, T2: after needle insertion, NS: no significant differences. *Mann-Whitney $U$ test was used for the comparison of MAPS score.
Group E with an $80 \%$ chance of detecting significance at the 5\% level.

\section{Results}

A total of 41 children were randomly assigned to either Group C or Group E. There was no significant difference between the two groups in gender, age, weight, height, and the duration of surgery or anesthesia (Table 2). From T0 to T1, MAPS scores showed no difference between the two groups, but MAPS scores were significantly lower in Group E compared with Group C at T2 ( $\mathrm{P}=0.001)$ (Table 3 ). Furthermore, the incidence of a significant pain response (MAPS $\geq 4$ ) when the needle was advanced into the sacral hiatus was significantly lower in Group $\mathrm{E}$ than in Group C ( $\mathrm{P}=0.019)$ (Table 4). At this point, the main different categories were body movement and heart rate. Especially, the incidence of rigid and/or limited body movements, which necessitated holding by the assistant along with 2-3\% sevoflurane inhalation for a safe procedure, was significantly lower in Group $\mathrm{E}$ than in Group C $(\mathrm{P}<0.001)$ (Table 5). Incidence of increase in heart rate by more than 10 beats/min was significantly lower in Group E than in Group C ( $\mathrm{P}=0.018)$ (Table 5).

In Group C, frequency of use of sevoflurane was higher due

Table 4. Incidence of Significant Pain Response Caused by Advancement of the Needle Into the Sacral Hiatus at T2

\begin{tabular}{ccc}
\hline & Group C $(\mathrm{n}=21)$ & Group E $(\mathrm{n}=20)$ \\
\hline MAPS $<4$ & $6(29)$ & $13(65)$ \\
MAPS $\geq 4$ & $15(71)$ & $7(35)^{*}$ \\
\hline
\end{tabular}

Data are presented as number of patients (\%). Group C: Placebo group, Group E: EMLA group, MAPS: Multidimensional Assessment Pain Scale, MAPS $\geq 4$ was considered as a significant pain response caused by advancement of the needle into the sacral hiatus. *Incidence of significant pain response caused by advancement of the needle into the sacral hiatus was significantly lower in Group E than in Group C $(\mathrm{P}<$ $0.05)$ by $x^{2}$-test.

Table 5. Incidence of Mainly Showing Difference in Category at T2

\begin{tabular}{|c|c|c|c|}
\hline & \multirow{2}{*}{$\begin{array}{l}\text { Incidence } \\
\text { of increase } \\
\text { in heart rate } \\
\text { by more than } \\
10 \text { beats/min }\end{array}$} & \multicolumn{2}{|c|}{ Body movements } \\
\hline & & $\begin{array}{c}\text { Restless body } \\
\text { movement }\end{array}$ & $\begin{array}{l}\text { Rigid and/or } \\
\text { limited body } \\
\text { movements }\end{array}$ \\
\hline Group E $(\mathrm{n}=20)$ & $3(15) *$ & $9(45)$ & $5(25)^{\dagger}$ \\
\hline Group C $(\mathrm{n}=21)$ & $10(48)$ & $4(19)$ & $17(81)$ \\
\hline
\end{tabular}

Data are presented as number of patients (\%). Group C: Placebo group, Group E: EMLA group. *Incidence of increase in heart rate by more than 10 beats/min was significantly lower in Group E than in Group C $(\mathrm{P}<0.05)$ by $x^{2}$-test. ${ }^{\dagger}$ Rigid and/or limited body movements showed a significantly lower incidence in Group E compared with Group C $(\mathrm{P}<$ $0.001)$ by $x^{2}$-test. 
Table 6. Incidence of Use of Sevoflurane during Caudal Block

\begin{tabular}{cccc}
\hline & Group C $(\mathrm{n}=21)$ & Group E $(\mathrm{n}=20)$ & P value* $^{*}$ \\
\hline T0 & $0(0)$ & $0(0)$ & NS \\
T1 & $1(4.8)$ & $0(0)$ & NS \\
T2 & $17(81)$ & $5(25)$ & $<0.001$ \\
\hline
\end{tabular}

Data are presented as number of patients (\%). Group C: Placebo group, Group E: EMLA group, T0: baseline values; T1: before needle insertion; T2: after needle insertion, NS: no significant differences. ${ }^{*} x^{2}$-test was used to compare the incidence of use of sevoflurane between the two groups.

to rigidity and/or limited body movements than that in Group $\mathrm{E}$ at T2 during caudal block $(\mathrm{P}<0.001)$ (Table 6). No specific complications such as breath holding or severe respiratory distress caused by pain were seen in any of the two groups during caudal block. Operation was performed successfully in all patients without additional fentanyl administration. Furthermore, in the recovery room after operation, we did not observe any complications such as seizure, cyanosis, convulsion, respiratory depression, cardiac arrhythmia caused by caudal block.

\section{Discussion}

The present study confirmed that the EMLA cream was effective in reducing MAPS scores associated with caudal block and the incidence of use of sevoflurane during caudal block. A significant reduction in MAPS scores was observed in the EMLA group compared with the control group at T2. Moreover, need for sevoflurane inhalation due to rigidity and/or limited body movements was significantly lower in Group E (25\%) compared with Group C (81\%) at T2.

Caudal block is the most popular regional anesthetic technique in children undergoing infraumbilical surgery. Especially, it not only plays the role of anesthesia itself but also provides adjunctive postoperative analgesia. Although caudal block is partly easy and safe, block failure is the most common complication. Recently, many studies have shown that ultrasound-guided caudal block can help to improve the success rate and decrease the number of attempts [7]. However, skills training is necessary for the use of ultrasound in regional anesthesia, and ultrasoundguided caudal block may not feasible in all clinics due to its high cost. Sacral cornu, a landmark for caudal block, is located more superficially than in adults and sacral interspaces remain nonfused until early adulthood [8]. Furthermore, feeling the 'pop' on penetrating the sacrococcygeal ligament helps to identify the caudal epidural space [9]. To increase the success rate and to decrease unintended complications under sedation, reduction in the injection-related pain caused by body movement and hemodynamic instability during caudal block may be of paramount importance.
EMLA cream has been widely used as a popular analgesic for pain after pediatric procedures such as venipuncture. This cream is an emulsion containing lidocaine and prilocaine, which is applied over the needle injection site, where it is absorbed into the skin. Many previous studies have shown that the EMLA cream is effective in reducing injection-related pain [10-12]. However, in contrast to these studies, some studies showed that EMLA cream applied on the venous puncture site, did not decrease the pain score significantly compared with the oral glucose group or placebo group $[5,13]$. In this study, the application of EMLA cream over the sacral hiatus before caudal anesthesia decreased the MAPS scores reflecting injection-related pain. In body movements, as one of the MAPS categories, rigid and/or limited body movements were significantly less in Group E compared with Group C (Table 5) and this consequently resulted in reduction in requirement of additional sevoflurane inhalation via a mask compared with that in Group C (Table 6). The intensity of restless body movement was weak. Therefore, it did not cause disturbance during the procedure and sevoflurane inhalation was needed. Furthermore, EMLA cream application effectively prevented the increase in heart rate during the procedure (Table 5). Caudal block did not cause a decrease in the heart rate in any cases of our study.

Despite the effectiveness of EMLA cream, a relatively long time to peak effect for adequate anesthesia may be impractical and inconvenient in many clinical situations. Generally, the application time recommended by manufacturers is about 60 minutes [14]. However, Hopkins et al. [15] showed that there is no correlation between efficacy and application time after 30 minutes of application. It can be suggested that further studies regarding shorter application time should be performed to establish the effectiveness of the cream. Besides the discomfort related to the application time, local skin reactions such as erythema, pallor, and itching may follow EMLA cream application [16]. However, we did not observe any adverse effects in the operation room and PACU.

Combined with caudal block, methods for maintaining airway patency included use of a laryngeal mask, face mask, and tracheal intubation. On comparison of different airway management techniques, the complication rate was the lowest in the face mask group [17]. In addition, face mask ventilation caused lower airway irritation compared with tracheal intubation [18]. Therefore, face mask sedation combined with caudal block is suggested as another option for pediatric patients undergoing infraumbilical surgery. Ketamine $1.5 \mathrm{mg} / \mathrm{kg}$ reduces the additional requirement for analgesia below $10 \%$ during pediatric procedures compared with $1.0 \mathrm{mg} / \mathrm{kg}$ in cases of laceration repair, incision and drainage, etc. [19]. But in this study, ketamine $1.5 \mathrm{mg} / \mathrm{kg}$ provided inadequate analgesia and frequent sevoflurane inhalation was required in patients of Group C (81\%). In 
pediatric sedation, there was an association between adverse outcomes and administration of number of sedative agents. Three or more agents used for sedation showed higher association with adverse outcomes. Furthermore, drug combination and interaction contributed to negative outcomes [20]. Only $1.8-2.0 \%$ sevoflurane sedation in pediatric patients on MRI was usually successful but hypoxia occurred in few cases [21]. In our experience from this study, 2-3\% sevoflurane via a face mask was required for prevention of rigid and/or limited body movements in the control group and $1 \%$ sevoflurane via a face mask was enough to achieve sedation during operation after caudal block in both groups. Furthermore, pediatric patients were sedated with ketamine and midazolam in the waiting room and sevoflurane was used as an additive if we needed more sedation during caudal block. Therefore, EMLA application over the sacral hiatus before caudal block reduces the number of drugs used for sedation during caudal block and may contribute to reducing adverse outcomes by less usage of sevoflurane during caudal block.
The limitation of this study was that we did not assess the extent to which EMLA cream affected lidocaine concentration in caudal block. We just applied EMLA cream over the sacral hiatus in the size of a coin and used 1\% lidocaine in the same dose for caudal anesthesia during infraumbilical surgery in our hospital previously.

In conclusion, this investigation showed that children receiving pre-treatment with EMLA cream before caudal block showed significantly lower MAPS scores and incidence of use of sevoflurane compared with the placebo group immediately after needle insertion. Therefore, we suggest that the use of EMLA cream before caudal block has significant advantages in alleviating procedure pain during caudal block.

\section{ORCID}

Eun Kyung Choi, http://orcid.org/0000-0001-5758-6741

Sung-Sik Park, http://orcid.org/0000-0001-5574-7513

Ki-bum Park, http://orcid.org/0000-0002-1432-8301

\section{References}

1. Dalens B. Regional anesthesia in children. Anesth Analg 1989; 68: 654-72.

2. Dalens B, Hasnaoui A. Caudal anesthesia in pediatric surgery: success rate and adverse effects in 750 consecutive patients. Anesth Analg 1989; 68: 83-9.

3. AstraZeneca. EMLA ${ }^{\circledR}$ Cream Package insert [Internet]. Mississauga, Canada [Cited 2013 Dec 7]. Available from http://www.astrazeneca.ca/ en/Our-Medicines/en-Products-AZ

4. Abuelkheir M, Alsourani D, Al-Eyadhy A, Temsah MH, Meo SA, Alzamil F. EMLA(R) cream: a pain-relieving strategy for childhood vaccination. J Int Med Res 2014; 42: 329-36.

5. Lal MK, McClelland J, Phillips J, Taub NA, Beattie RM. Comparison of EMLA cream versus placebo in children receiving distraction therapy for venepuncture. Acta Paediatr 2001; 90: 154-9.

6. Ramelet AS, Rees NW, McDonald S, Bulsara MK, Huijer Abu-Saad H. Clinical validation of the Multidimensional Assessment of Pain Scale. Paediatr Anaesth 2007; 17: 1156-65.

7. Ponde VC. Recent developments in paediatric neuraxial blocks. Indian J Anaesth 2012; 56: 470-8.

8. Dadure C, Sola C, Dalens B. Capdevila X. Regional anesthesia in children. In: Miller's Anesthesia. 8th ed. Edited by Miller RD: Philadelphia, Churchill Livingstone/Elsevier. 2015, pp 2722-3.

9. Tsui BC, Tarkkila P, Gupta S, Kearney R. Confirmation of caudal needle placement using nerve stimulation. Anesthesiology 1999; 91: 374-8.

10. Young SS, Schwartz R, Sheridan MJ. EMLA cream as a topical anesthetic before office phlebotomy in children. South Med J 1996; 89: 1184-7.

11. Robieux I, Kumar R, Radhakrishnan S, Koren G. Assessing pain and analgesia with a lidocaine-prilocaine emulsion in infants and toddlers during venipuncture. J Pediatr 1991; 118: 971-3.

12. Wig J, Johl KS. Our experience with EMLA Cream (for painless venous cannulation in children). Indian J Physiol Pharmacol 1990; 34: 1302 .

13. Gradin M, Eriksson M, Holmqvist G, Holstein A, Schollin J. Pain reduction at venipuncture in newborns: oral glucose compared with local anesthetic cream. Pediatrics 2002; 110: 1053-7.

14. Lawson RA, Smart NG, Gudgeon AC, Morton NS. Evaluation of an amethocaine gel preparation for percutaneous analgesia before venous cannulation in children. Br J Anaesth 1995; 75: 282-5.

15. Hopkins CS, Buckley CJ, Bush GH. Pain-free injection in infants. Use of a lignocaine-prilocaine cream to prevent pain at intravenous induction of general anaesthesia in 1-5-year-old children. Anaesthesia 1988; 43: 198-201.

16. Evers H, von Dardel O, Juhlin L, Ohlsén L, Vinnars E. Dermal effects of compositions based on the eutectic mixture of lignocaine and prilocaine (EMLA). Studies in volunteers. Br J Anaesth 1985; 57: 997-1005.

17. Bordet F, Allaouchiche B, Lansiaux S, Combet S, Pouyau A, Taylor P, et al. Risk factors for airway complications during general anaesthesia in paediatric patients. Paediatr Anaesth 2002; 12: 762-9. 
18. Tiret L, Nivoche Y, Hatton F, Desmonts JM, Vourc'h G. Complications related to anaesthesia in infants and children. A prospective survey of 40240 anaesthetics. Br J Anaesth 1988; 61: 263-9.

19. Heilbrunn BR, Chang TP, Liu DR. A retrospective comparison of ketamine dosing regimens for pediatric procedural sedation. Eur J Emerg Med 2015; 22: 111-6.

20. Coté CJ, Karl HW, Notterman DA, Weinberg JA, McCloskey C. Adverse sedation events in pediatrics: analysis of medications used for sedation. Pediatrics 2000; 106: 633-44.

21. De Sanctis Briggs V. Magnetic resonance imaging under sedation in newborns and infants: a study of 640 cases using sevoflurane. Paediatr Anaesth 2005; 15: 9-15. 